\title{
LA EXPANSIÓN DEL DERECHO A LA INTEGRIDAD: EL CASO DE LOS TRANSGÉNEROS
}

\author{
Raúl CANosa Usera \\ Departamento de Derecho Constitucional \\ Facultad de Derecho \\ Universidad Complutense de Madrid \\ rcanosa@ucm.es
}

\begin{abstract}
RESUMEN
Se analizan las implicaciones jurídicas derivadas de la situación de los denominados «transgénero» como categoría sexual específica a los efectos de medir su inserción jurídica y constitucional, teniendo en cuenta tanto el plano normativo como el jurisprudencial europeo y americano.

Palabras clave: sexualidad, transgénero, integridad, Constitución, jurisprudencia, personalidad.
\end{abstract}

\section{ABSTRACT}

We look into the legal implications derived from the special situation of the socalled «transgender» individuals as a specific sex category to the point of observing its legal and constitutional implications, considering both its legal point of view and the one by EU or American case law.

Keywords: Sex, transgender, integrity, Constitution, Case law, character

\section{ZUSSAMENFASSUNG}

Es werden die juristischen Auswirkungen untersucht, die sich aus der Situation der sogenannten «Transsexuellen» als geschlechtsspezifischer Kategorie bezogen auf ibre juristische und verfassungsrechtliche Einordnung ergeben. Hierbei wird der europäische und amerikanische Rechtsrahmen sowie die einschlägige Rechtsprechung berücksichtigt.

Schlüsselwörter: Sexualität, Transsexualität, Integrität, Verfassung, Rechtsprechung, Persönlichkeit.

SUMARIO: I. UN DERECHO CONTROVERTIDO, PERO EN EXPANSIÓN.II. TRANSGÉNEROS E INTEGRIDAD PERSONAL.-III. DERECHOS DE LOS TRANSGÉNEROS EN LA JURISPRUDENCIA DEL TEDH.-1. La primera negativa.-2. El derecho a la identidad sexual.-3. Derecho de acce- 
so a los tratamientos de reasignación sexual.-4. Otros casos relacionados con transexuales.-5. El último paso dado: el caso A. P., Garçon y Nicot c. Francia, de 6 de abril de 2017.-IV. LA CORTE INTERAMERICANA EN LA VANGUARDIA.-V. LA VIGENTE LEGISLACIÓN ESPAÑOLA.VI. TRANSGÉNEROS Y DERECHOS A LA SALUD EN LA CARTA SOCIAL EUROPEA.-VII. CONCLUSIÓN.

\section{UN DERECHO CONTROVERTIDO, PERO EN EXPANSIÓN}

Cuando el art. 16 de la Declaración de Derechos del Hombre y del Ciudadano de 1789 dispone que «donde no hay garantía de los derechos ni división de poderes no hay constitución», no aclara, sin embargo, cuáles derechos deben ser reconocidos. Ni siquiera las primeras declaraciones francesas coincidían siempre en los derechos que proclamaban.

Pareciera hoy que los viejos derechos naturales han sido sustituidos por los derechos humanos declarados en el Derecho internacional y que, entre estos, aquellos protegidos por tribunales internacionales conformarían ese núcleo indispensable al que ligamos lo materialmente constitucional. Sin embargo, no hay coincidencia absoluta entre los mismos tratados y tampoco entre estos y las declaraciones constitucionales. Es decir, el ius commu$n e$, del que con tanta frecuencia se habla, en ocasiones no es tan común.

Y uno de los ejemplos de divergencia es justamente el derecho a la integridad, reconocido en la Convención Americana de Derechos Humanos (en adelante, $\mathrm{CADH}$ ), pero no en el Convenio Europeo de Derechos Humanos (en adelante, CEDH). Porque, en general, los textos internacionales y constitucionales protegen la integridad frente a torturas, penas y tratos inhumanos o degradantes, pero no siempre proclaman el derecho a la integridad personal ${ }^{1}$.

Estas diferencias de reconocimiento se dan también en el caso de la prohibición de la esclavitud, presente en los textos internacionales, pero ausente en los constitucionales. Es cierto que la esclavitud, al menos en sus manifestaciones formales, ha desaparecido de la vida, al punto de no requerirse su proclamación constitucional, pero no sucede lo mismo con la protección de la integridad, porque allí donde no se reconoce un derecho específico, sus principales contenidos acaban protegiéndose por otras vías. El punto, pues, no es que sobre la integridad no pesen peligros cier-

\footnotetext{
${ }^{1}$ Sobre esta problemática cfr. R. CANOSA UsERA, El derecho a la integridad personal, Valladolid, Lex Nova, 2006.
} 
tos, sino justo lo contrario, están aumentando, así que allí donde no hay reconocimiento expreso del derecho a la integridad se han hallado fórmulas para protegerla en las situaciones de la vida donde esta esté en peligro, y para defenderla no basta, en tales casos, la prohibición de torturas y tratos inhumanos o degradantes.

El ejemplo canónico de este proceder lo ofrece el Tribunal Europeo de Derechos Humanos (en adelante, TEDH), que ha incluido los contenidos del derecho a la integridad física y psicológica — que no cabe incluir en la prohibición de torturas - en el macroderecho a la vida privada y familiar proclamado en el art. $8 \mathrm{CEDH}$. En efecto, este precepto no se limita ya a proteger el bien jurídico vida privada, sino que protege también la integridad (aparte algunas decisiones de la Comisión, la primera del TEDH fue el caso X. e Y. c. Holanda, de 26 de mayo de 1985, y luego Pretty c. Reino Unido, de 29 de abril de 2002, e Y. F. c. Turquía, de 22 de julio de 2003), al punto de acabar refiriéndose abiertamente al «derecho a la integridad» (caso Glass c. Reino Unido, de 9 de marzo de 2004).

Vemos, pues, que el TEDH ha tenido que efectuar una interpretación evolutiva para proteger situaciones de la vida que, afectando a la integridad, no podían calificarse como torturas o tratos inhumanos y recibir la cobertura del art. $3 \mathrm{CEDH}$. La cobertura por vía interpretativa ha venido del art. 8, un verdadero cajón de sastre donde el TEDH ha ubicado derechos nuevos. En contraste, la Corte Interamericana, al disponer de una proclamación específica del derecho a la integridad física, psíquica y moral, no necesita operar creativamente, sino limitarse a señalar cuándo el expreso derecho a la integridad es vulnerado.

\section{TRANSGÉNEROS E INTEGRIDAD PERSONAL}

Se decía para ilustrar la omnipotencia del Parlamento inglés que este lo podía todo, salvo cambiar un hombre en mujer y viceversa. Tales cosas hace tiempo que son posibles y han venido originando una larga controversia jurídica que todavía hoy se está ventilando. Como es sabido, la identidad sexual de las personas, reflejada en sus documentos oficiales, venía determinada en exclusiva por su sexo de origen, de suerte tal que no cabía cambio alguno. Tal identidad era indisponible para la persona y esta indisponibilidad nutría la seguridad jurídica. Mientras la transformación física del sexo no fue posible, la operatividad de estos dos principios (seguridad jurídica e indisponibilidad del estado civil) no fue puesta seriamente 
en jaque, aunque siempre haya habido personas que pudieran actuar de acuerdo con las características del sexo opuesto al suyo natural.

La verdadera revolución se produjo cuando la cirugía y otros tratamientos médicos consintieron el cambio de sexo, lo que abrió la puerta a que los anhelos de los transexuales se cumplieran en un plano antes imposible. A la vivencia psicológica de sentirse del otro sexo se podía ahora añadir la experiencia de transformar el cuerpo para que sus atributos sexuales se acompasaran a los psicológicos.

Sin embargo, esa transformación física requería, para implicar plenitud, que también los documentos oficiales reflejaran la nueva identidad sexual, y entonces toparon con los dos principios aludidos, el de seguridad jurídica y el de indisponibilidad. A lo anterior se añadió después el deseo de quienes no querían o no podían someterse a cirugía o a otros tratamientos de radical transformación física. Estas personas deseaban cambiar la identidad de género de sus documentos oficiales, pero sin cambio de sexo. Es decir, desligando la identidad sexual (plano físico) de la identidad de género (plano psicológico). El anhelo final sería, pues, obtener el cambio de los papeles oficiales sin cambio físico de sexo.

En suma, se trata de determinar si los deseos de estas personas, los transgéneros, encajan en alguno de los derechos proclamados tanto por los documentos internacionales como por los nacionales. Y comprobamos que, en efecto, desde hace pocos años se han producido cambios radicales en las legislaciones nacionales, en buena medida en desarrollo de decisiones jurisprudenciales en las que se iba encontrando acomodo a los deseos de los transgéneros en el contenido de derechos fundamentales.

Por este motivo, ante las situaciones vitales de estas personas, los ordenamientos podían responder eventualmente con la proclamación de derechos específicos a su favor. Tal proceder, por lo demás tan común hoy en las declaraciones de derechos (derechos de las mujeres, de los niños, de los mayores, de los discapacitados, etc.), conlleva el riesgo de fragmentar la protección de los derechos al hacerlo con su titularidad, que por definición debe ser universal; solo así podemos hablar de verdaderos derechos y no de privilegios. Por ello, la alternativa a la postre preferida ha sido la de la interpretación jurisprudencial, mediante la cual se ha concretado de qué modo las personas trans ejercen sus derechos a la vida privada o a su integridad, principalmente. Es obvio que el desarrollo concreto de los procedimientos necesarios para que ese ejercicio se produzca corresponde al legislador, pero este estaría desarrollando el derecho a la integridad o a la vida privada, por ejemplo, para su particular ejercicio por parte de estas personas. 
En todo caso, diversos organismos internacionales, además de los tribunales internacionales cuya jurisprudencia más tarde examinaremos, se han venido pronunciando en los últimos años de manera cada vez más inequívoca en apoyo de las tesis en favor de los transgéneros. Así, en el ámbito del Consejo de Europa, ya en 2009, el comisario de derechos humanos en un documento temático («Los derechos humanos y la identidad de género») señaló claramente los problemas relativos a la transexualidad y las medidas que los Estados estaban adoptando para resolverlos. Específicamente se refirió a las condiciones de cambio de sexo y de nombre, acerca de las cuales alertó de que exigir la esterilización u otros tratamientos médicos radicales era contrario al derecho a la integridad física. Concluyó con una clara recomendación: «dejar de condicionar el reconocimiento de la identidad de género de una persona a una obligación legal de esterilización o de sometimiento a otros tratamientos médicos».

En 2010 el Comité de Ministros acordó, por su parte, una recomendación a los Estados para que evaluasen periódicamente las condiciones impuestas para efectuar el reconocimiento de cambio de género. Más claramente, la Asamblea Parlamentaria, también en 2010, insistió en garantizar el derecho a recibir documentos oficiales que reflejasen la identidad del género escogida sin obligación de someterse previamente a «esterilización u otros procedimientos médicos tales como operaciones de conversión sexual o terapia hormonal».

Más recientemente, en 2015, la Asamblea Parlamentaria aprobó una resolución llamando a los Estados a instaurar «procedimientos rápidos, transparentes y accesibles, basados en la autodeterminación», comprendiendo la supresión de «la esterilización y otros tratamientos médicos obligatorios».

Por su parte, en el ámbito de Naciones Unidas, conviene subrayar que en 2011 el Alto Comisionado de los Derechos Humanos presentó un informe sobre las prácticas discriminatorias de las que eran víctimas, en razón de su orientación sexual, también los transexuales. En él recomendaba a los Estados facilitar el reconocimiento jurídico del género de preferencia sin que al hacerlo se atentase contra otros derechos humanos.

Igualmente, el Rapporteur General sobre la tortura recomendó, en 2013, que se aboliese toda forma de esterilización forzada en general y en particular en relación con los transexuales, objetivo en el que coincidieron el Alto Comisionado de los Derechos Humanos de Naciones Unidas, la Organización Mundial de la Salud (en adelante, OMS) y Unicef en una declaración común. El mismo objetivo que reitera el citado Rapporteur General sobre la tortura en su informe de 2016. 


\section{DERECHOS DE LOS TRANSGÉNEROS EN LA JURISPRUDENCIA DEL TEDH}

\section{La primera negativa}

En el contexto internacional señalado la labor del TEDH ha sido muy destacada, ya que ha fijado un estándar común de protección de los derechos de los transgéneros. Ello a pesar de que en un primer momento se negó a dar los pasos que luego dio con seguridad. Así, en los primeros casos en los que el TEDH se planteó la transexualidad lo hizo a propósito del reconocimiento legal de la condición sexual real de quienes se habían sometido a operaciones y tratamientos médicos de cambio de sexo. En estos primeros asuntos (casos Rees, de 17 de octubre de 1986; Sheffield y Horshamm, de 30 de julio de 1998, y Cossey, de 27 de septiembre de 1991, los tres contra el Reino Unido) el TEDH no consideró la vulneración ni del art. 8 ni del art. 12 (derecho a casarse). Con todo, afirmó ser consciente de la gravedad de los problemas ligados a la transexualidad y sugirió que había que estar atentos, también los Estados, a la evolución de la ciencia y de la sociedad (casos Rees y Sheffiled).

Sin embargo, en su decisión de 25 de marzo de 1992, caso B. C. c. Francia, el TEDH declaró por primera vez la violación del art. 8 CEDH, debido al no reconocimiento oficial de la identidad sexual de la víctima que, a diferencia de los casos ingleses, en Francia sufría incomodidades cotidianas incompatibles con el disfrute de su vida privada.

\section{El derecho a la identidad sexual}

Es, sin embargo, en un caso contra el Reino Unido, el célebre caso Christine Goodwin, de 21 de julio de 2002, donde el TEDH afirma el derecho a la identidad sexual enclavándolo en el derecho a la vida privada. Tal derecho implica tomar decisiones sobre la propia vida privada que incluye, como ya se ha explicado, la integridad personal, tanto física como psicológica, ligada a la autonomía personal y a la dignidad. Por tanto, la identidad sexual es un elemento central de la vida privada, lo que ya había dicho con anterioridad en general, y que la cobertura a los anhelos de los transexuales. Esta doctrina se ha mantenido desde entonces en todas las decisiones del TEDH, sentando así la base de que el ejercicio del derecho a la 
vida privada y a la integridad ha de permitir a los transexuales vivir su transexualidad con el resguardo del derecho reconocido en el art. $8 \mathrm{CEDH}$. Los Estados violarían este derecho si sus normas internas fueran incompatibles con este aspecto crucial de la identidad personal.

La víctima del caso, Christine Goodwin, ya se había sometido a un cambio físico de reasignación de sexo y había adquirido así la identidad física de una mujer; sin embargo, en su partida de nacimiento seguía costando como hombre y cuando solicitó el cambio en esta y en el resto de los documentos oficiales las autoridades británicas se negaron. Ante esta situación, el TEDH acaba concluyendo que existe un derecho a que la nueva identidad sexual sea reconocida por las autoridades y, en consecuencia, estas deben proceder a la modificación de los documentos oficiales. Esta doctrina se reitera en otros casos en los que no se producía el reconocimiento (Cassar c. Malta, de 9 de julio de 2013, y Hämäläinen c. Finlandia, de 16 de julio de 2014).

\section{Derecho de acceso a los tratamientos de reasignación sexual}

En el siguiente paso el TEDH acabó reconociendo el derecho de acceso a los tratamientos médicos que permiten el cambio de sexo, ligando tal acceso en condiciones de igualdad a la salud de los transexuales. Porque uno de los derechos no proclamados en el CEDH pero que el TEDH ha acabado parcialmente protegiendo es el derecho a la salud. Y aquí está en juego la salud tanto física como psíquica de los transexuales. Si estos viven en el sexo opuesto y anhelan cambiarlo para poner en consonancia su identidad de género con la sexual, el acceso a los tratamientos que lo permitieran era el siguiente paso que el TEDH acabó dando.

Si existe un derecho a la identidad sexual y esta la ejercen los transexuales cambiando su conformación sexual de nacimiento, el Estado no puede obstaculizar esa decisión (obligación negativa) y debe favorecerla (obligación positiva), primero, con el reconocimiento del cambio cuando se produce y, asimismo, facilitando el acceso a los tratamientos médicos. Es en el caso Van Kück c. Alemania, de 12 de junio de 2003, cuando por primera vez se afirma tal cosa. La víctima había exigido sin éxito ante los tribunales nacionales de su compañía aseguradora privada el reembolso de los gastos complementarios generados por su conversión sexual. El TEDH considera contrario al art. 8 convencional que los tribunales cuestionaran la necesidad del tratamiento, pues es desproporcionado exigir a 
la víctima la prueba de la necesidad médica en un ámbito tan íntimo de su vida privada.

En otros casos posteriores, el TEDH ha reafirmado aún más claramente ese derecho de acceso a los tratamientos en supuestos en los que se impide el acceso a los mismos, bien por existir laguna legislativa en el desarrollo del derecho a cambiar de sexo que impide de facto el acceso a los tratamientos médicos pertinentes (caso L. c. Lituania, de 11 de septiembre de 2007) o bien porque los tribunales o las autoridades nacionales deniegan ese acceso (casos Y. Y. c. Turquía, de 10 de marzo de 2015, y D. C. c. Turquía, de 7 de febrero de 2017).

\section{Otros casos relacionados con transexuales}

Se trata de supuestos en los que están en juego otros aspectos de la vida privada de los transexuales, pero no directamente relacionados con su integridad. Así, en el caso X., Y. y Z. c. Reino Unido, de 22 de abril de 1992, aunque el TEDH no aprecia violación del art. 8, sienta el precedente de que existe una vida familiar entre un transexual y el hijo de su pareja. O en el caso Grant c. Reino Unido, de 23 mayo de 2006, en el que se dice que del reconocimiento oficial de la nueva identidad se han de derivar todas las eventuales consecuencias que lleva aparejada, incluyendo la de percibir las pensiones que, como a las otras mujeres, pudiera corresponder a la víctima en ese caso.

\section{El último paso dado: el caso A. P., Garçon y Nicot c. Francia, de 6 de abril de 2017}

En este importante asunto se da un paso decisivo, consistente en considerar que la exigencia de esterilización o de tratamiento que entraña riesgo de producirla es contraria al art. 8 convencional y la esterilización en sí sería potencialmente contraria también al art. 3 convencional. La importancia de esta decisión reside en que hasta ese momento el TEDH se había limitado a resolver asuntos que, como hemos visto, concernían al reconocimiento oficial de la nueva identidad sexual que los demandantes habían adquirido a través de intervenciones quirúrgicas u otros tratamientos médicos, y, eventualmente, a las consecuencias de tales cambios en la condición jurídica de los afectados, o bien se referían al acceso a tales tratamientos. 
Sin embargo, en el caso que comentamos el punto de vista se desplaza a la posibilidad, reclamada por los activistas de los derechos de las personas trans, de reclamar ese cambio en los documentos oficiales sin necesidad de someterse a operaciones $\mathrm{u}$ otro tipo de tratamientos o intervenciones médicas que conlleven la esterilización o que entrañen riesgo de sufrirla.

Como es sabido, las primeras modificaciones legislativas estatales, generadas en buena parte por la ya comentada jurisprudencia del TEDH, aceptaron el reconocimiento oficial de la nueva identidad sexual con la condición de que el cambio de sexo se hubiera operado efectivamente en el cuerpo de quien la reclamaba. Es decir, la identidad de género se ligaba a la efectiva identidad sexual, siguiendo el patrón de la asignación al sexo de nacimiento, solo que aceptando que el de origen podía médicamente transformarse y, como resultado de tal transformación, modificarse también la asignación oficial. Así las cosas, la exigencia de que el cambio efectivo de sexo se hubiera producido resultaba ser condición del cambio en los documentos oficiales; este último cambio dependía de aquel.

Poco a poco las legislaciones nacionales de los Estados miembros del Consejo de Europa se tuvieron que ir adaptando al estándar fijado por el TEDH y dentro de él algunos aprovecharon su margen de apreciación para ir más lejos en una línea, por lo demás, apuntada reiteradamente por informes y acuerdos de organismos internacionales que ya hemos mencionado, a saber, que no era respetuoso de los derechos de los transexuales exigir esa transformación física para reconocerles la identidad de género que deseaban. Entre otras cosas, porque los tratamientos médicos pueden poner en riesgo la salud de los afectados o directamente estos pueden no desear someterse a ellos. Y si la toma de decisiones sobre la sexualidad, en general, y sobre la propia identidad sexual, en particular, es parte nuclear de la vida privada y la integridad de las personas, condicionar su ejercicio a someterse a tales tratamientos sería contrario al ejercicio de sus derechos y atentatorio de su dignidad y autonomía personales.

Ha tenido que ser la decisión del TEDH en el caso A. P., Garçon y Nicot la que permitiera incorporar estas tesis, que ya se habían materializado en las legislaciones de algunos Estados, entre ellos España, pero que, a falta de un estándar marcado por el TEDH, aún quedaban al albur de los Estados. Estos deberán ahora eliminar el requisito de la esterilización o de tratamientos que entrañen el riesgo de sufrirla.

La decisión del TEDH ha sido arriesgada porque no había un consenso europeo en la materia, pues el principio de indisponibilidad de la asig- 
nación de la identidad sexual, ligado al sexo de nacimiento, y el principio de seguridad jurídica justificaba la negativa a reconocer cualquier modificación de reasignación de nacimiento salvo, tras la doctrina primera del TEDH ya explicada, cuando se demostraba el cambio efectivo de sexo de nacimiento que ya la ciencia permitía acometer.

Con la nueva decisión del TEDH se da un paso de gigante al romper la conexión de la identidad de género con la sexual, de tal suerte que queda al albur del individuo decidir si se somete a los tratamientos o no, sin que la decisión de no someterse a ellos le impida reclamar el cambio de identidad de género en la documentación oficial. El TEDH hace suya la principal reivindicación de los movimientos transgéneros, la cual ya muchos organismos internacionales habían asumido.

En el caso A. P., Garçon y Nicot se resuelven acumulados tres casos en los que se discute la legislación francesa - por cierto, modificada después en 2016 - , es decir, que estamos ante un caso de control normativo, de control de convencionalidad en suma. A la sazón, la legislación francesa exigía, para proceder a la modificación del sexo en los documentos oficiales, dos requisitos: acreditar la realidad del síndrome transexual, así como la irreversibilidad en la transformación de la apariencia física.

Frente a esta legislación, el primer recurrente, que se había sometido a una operación de reasignación de sexo en el extranjero, se niega a pasar la prueba pericial y obtiene el cambio de nombre en los papeles oficiales, pero no el de sexo. Por su parte, el segundo reclamante solo demuestra haberse sometido a ciertos tratamientos, así que no obtiene ni una cosa ni la otra. Por último, el tercer demandante no acredita ningún tratamiento, solo que vive con apariencia de mujer, y se niega someterse a la pericial que la ley francesa requería, y, en consecuencia, también ve rechazada su solicitud en el foro nacional.

A la vista de los hechos, el TEDH acaba creando el derecho a escoger el sexo en los documentos oficiales sin necesidad de someterse a una operación o tratamiento médico que pudiera implicar la esterilización. Sin embargo, tiene en cuenta los principios de seguridad jurídica e indisponibilidad del estado civil y por ello acaba considerando no contrarias al $\mathrm{CEDH}$ dos exigencias: la primera, que los interesados en obtener ese cambio en sus documentos deban acreditar la realidad del síndrome de transexualismo, tal y como exigía la legislación francesa; la segunda, exigir al transexual que se someta a un examen médico, lo que también contemplaba la legislación francesa. Así, los Estados pueden introducir este tipo de requisitos en virtud de su margen de apreciación. 
Con estas últimas precisiones el TEDH acaba completando y perfilando los contornos del derecho, que hasta este momento y a la vista de su entera jurisprudencia implicaría:

- El derecho al reconocimiento de la identidad de género de adopción con independencia de si el sujeto se ha sometido a operaciones o tratamientos de reasignación sexual.

- El derecho a disfrutar de todas las consecuencias ligadas a la pertenencia al sexo adquirido, sin discriminación.

- El derecho a acceder a los tratamientos médicos de reasignación.

Sin embargo, el TEDH permite a los Estados la posibilidad de introducir requisitos que habrían de cumplir los reclamantes de los cambios documentales, siempre que fueran compatibles con el CEDH. Entre ellos admite el de comprobación de la existencia del síndrome de transexualismo o el de la prueba pericial.

\section{LA CORTE INTERAMERICANA EN LA VANGUARDIA}

En una reciente opinión consultiva solicitada por Costa Rica y titulada «Identidad de género e igualdad y no discriminación a parejas del mismo sexo», la Corte se explaya en prolijas consideraciones acerca de las obligaciones estatales en relación con el cambio de nombre, la identidad de género y los derechos derivados del vínculo entre parejas del mismo sexo. Fija así el alcance, en relación con estos asuntos, de los arts. 1.1, 3, 7, 11.2, 13, 17, 18 y 24 de la Convención, en relación todos ellos con las obligaciones para los Estados derivadas del art. 1 convencional.

Respecto a la integridad sexual, la Corte la liga, como hizo el TEDH, a la identidad que este último encuadra en la vida privada y que la Corte puede abiertamente encajar en el específico precepto convencional que reconoce el derecho a la integridad física, psíquica y moral (art. 5). Así las cosas, la Corte no tiene que argumentar, como ha tenido que hacerlo el TEDH, desde el derecho a la vida privada que también la Convención reconoce (art. 11.2), sino desde el específico derecho a la integridad que no existen en el CEDH y que el TEDH incorporó al macroderecho a la vida privada (art. $8 \mathrm{CEDH}$ ).

Es obvio que todo lo relativo al cambio de sexo afecta principalmente tanto a la vida privada como a la integridad, esta última no solo en su dimensión física, sino también en la psicológica y en la moral. 
En relación con los transgéneros, la Corte va más lejos que el mismo TEDH, al que por lo demás cita en abundancia. Va más lejos porque hace prevalecer la voluntad del sujeto que desea cambiar de identidad de género en los documentos oficiales sobre cualquier otra consideración. Obviamente, parte del derecho al reconocimiento de la identidad de género escogida, que, además, en la CADH viene reforzado con el «derecho a la personalidad jurídica» (art. 3). Este derecho a la identidad de elección, también encuadrable en el derecho a la vida privada (art. 11.2), tendría que ser reconocido por el Estado (parágrafos 102 y ss.), sobre el que pesaría la obligación de establecer un procedimiento sencillo, basado solo en el consentimiento libre e informado del sujeto (parágrafos 127 y ss.). De ello se desprende que el individuo podría eventualmente someterse a intervenciones quirúrgicas o tratamientos médicos mediante los cuales se produjera una reasignación de sexo. En este caso se estaría ejerciendo el derecho a la integridad física, disponiendo el titular de este derecho para aceptar semejantes tratamientos, por lo demás muy radicales y peligrosos para la salud. Podría, empero, darse la circunstancia de que el individuo no desease someterse a tales intervenciones médicas, bien por su peligrosidad o bien por otros motivos. Y hemos comprobado como el TEDH ha considerado que tales tratamientos no podrían imponerse, porque si así se hiciera, se haría depender el ejercicio del derecho a la identidad sexual de un sacrificio de la integridad física, en cierto modo impuesto al venir viciando el consentimiento.

La Corte comparte este punto de vista (parágrafos 145 a 148) y va aún más allá al considerar que tampoco otros requisitos serían legítimos a la luz de la Convención, puesto que el procedimiento para la modificación del estado civil ha de basarse únicamente en la voluntad del sujeto. De ello se infiere que la comprobación del síndrome de transexualidad o la prueba pericial serían contrarios a la obligación estatal de favorecer el ejercicio del derecho a la identidad de género que con tanto ardor defiende la Corte. Y lo hace distinguiendo nítidamente entre identidad sexual e identidad de género. Para el cambio en esta última debería requerirse únicamente la voluntad del sujeto y este, por su parte, es libre, ejerciendo su derecho a la integridad física, de someterse a tratamientos o cirugías que impliquen reasignación de su identidad sexual. 


\section{LA VIGENTE LEGISLACIÓN ESPAÑOLA}

España fue uno de los primeros países en modificar su legislación en la materia. Fue con la Ley 3/2007, de 15 de marzo, reguladora de la rectificación registral de la mención relativa al sexo de las personas. En ella se encomienda a los registros civiles (art. 3) la tarea de atender las solicitudes de cambio en asignación registral del sexo, que ha de venir acompañada del correspondiente cambio de nombre para que no haya discordancia con el sexo registral (art. 1). La legitimación se reserva a las personas de nacionalidad española mayores de edad (art. 1), lo que parecía lógico, ya que los registros españoles solo disponen de las partidas de los nacidos en España.

En relación con los requisitos, el art. 4 de la Ley exige la acreditación por los solicitantes de un informe médico o de psicólogo clínico donde quede diagnosticada la disforia de género y, en concreto, que haya disonancia persistente entre el sexo morfológico de nacimiento y la identidad de género o sexo psicosocial, así como la ausencia de trastornos de personalidad relevantes.

Asimismo, la persona solicitante ha de acreditar, con un informe médico, que ha sido tratada médicamente durante al menos dos años para acomodar sus características físicas a las correspondientes al sexo reclamado. Sin embargo, tales tratamientos no habrán necesariamente de incluir la cirugía de reasignación sexual, incluso podrán ser omitidos si concurriesen «razones de salud o edad que imposibiliten su seguimiento», aportando certificación médica de ello.

Como puede apreciarse tras este somero repaso a la legislación española, su regulación probablemente respetaría la doctrina comentada del TEDH y se movería en el margen de la apreciación estatal; por una parte, porque no exige la reasignación quirúrgica, aunque sí ciertos tratamientos que no necesariamente serían contrarios al parecer del TEDH (más aún cuando la ley española dispensa de tales tratamientos médicos por razones de salud), y, por otra, porque el TEDH, como se ha subrayado anteriormente, no considera que la exigencia de acreditar el padecimiento de la disforia de género sea contraria al CEDH.

La ley española, sin embargo, no superaría el examen a la luz de la doctrina de la $\mathrm{CADH}$, que, como hemos visto, descarta cualquier exigencia de tratamiento médico y hace depender el cambio exclusivamente de la voluntad de sujeto. 
Las cosas podrían cambiar en España si fuera finalmente aprobada la proposición de ley presentada por el PSOE y que fue tomada en consideración por el Congreso de los Diputados el pasado noviembre de 2017. En ella se elimina el requisito de presentar informes médicos; por tanto, bastaría la mera voluntad del solicitante (en línea con la $\mathrm{CADH}$ ). Además, la proposición incluye la posibilidad del cambio de sexo registral de los menores con su sola voluntad si tienen dieciséis años y solicitan por ellos mismos dicho cambio o con la solicitud de sus padres si son menores de dicha edad. Completa el panorama de las modificaciones propuestas la apertura del cambio para los extranjeros.

Por otro lado, desde la entrada en vigor de la Ley de 2007 varias Comunidades Autónomas se han ocupado de la materia en el ámbito de sus competencias, con frecuencia reconociendo generosamente derechos a las personas trans. En este sentido véanse, por ejemplo, los arts. 3 a 6 de la Ley $2 / 2016$, de 29 de marzo, sobre identidad y expresión de género e igualdad social y no discriminación de la Comunidad de Madrid.

\section{TRANSGÉNEROS Y DERECHOS A LA SALUD EN LA CARTA SOCIAL EUROPEA}

La ofensiva de los movimientos de transgéneros en todos los frentes para librar las batallas jurídicas que les permitieran ejercer sus derechos tal y como ellos los entendían tenía que llegar también al Comité Europeo de Derechos Sociales (en adelante, CEDS), encargado de hacer valer la Carta Social Europea (en adelante, CSE). En esta el derecho que podía ser invocado era el derecho a la salud (art. 11), que el propio CEDS había ligado en alguna de sus observaciones interpretativas y en alguna de sus decisiones a los arts. 2 y 3 CEDH. Por otro lado, en el procedimiento de revisión de los informes gubernamentales (monitoring system), el CEDS ya había formulado preguntas a los gobiernos, en relación con el art. 11.1 CSE, acerca de cómo se regulaba la cuestión de los transexuales.

$\mathrm{Al}$ resolver recientemente la reclamación colectiva 117/2015, Transgender Europe e ILGA-Europe c. República Checa, de 15 de mayo de 2018, el CEDS contribuye a conformar la nueva realidad que apuntaló el TEDH en el caso ya analizado A. P., Garçon y Nicot. Es más, sin esta decisión y el novedoso estándar en ella establecido, el CEDS habría tenido mucho más difícil pronunciarse como lo hizo. En efecto, en la reclamación colectiva 117/2015 se pusieron de manifiesto las estrechas relaciones entre los 
derechos reconocidos en el CEDH y los recogidos en la CSE, concretando en su caso la indivisibilidad entre ellos que tantas veces se ha proclamado en el Derecho internacional y, por supuesto, en el ámbito del Consejo de Europa. Porque si el ejercicio del derecho a la identidad sexual y de género (derecho a la vida privada) se ve condicionado por la obligación de someterse a una radical intervención médica, el afectado no prestaría un consentimiento completamente libre; al contrario, sería un consentimiento materialmente forzado, viciado, porque solo prestándolo y sometiéndose a la intervención en la integridad física podría ejercer su derecho al reconocimiento del estado civil deseado. Es decir, el ejercicio de este derecho estaría condicionado al sacrificio de la integridad física.

Si el TEDH hubiera considerado que los Estados podían mantener semejante requisito — que pudiera implicar la esterilización — para atender los principios de seguridad jurídica y de indisponibilidad del estado civil, y lo hubiera considerado, por tanto, ajustado al CEDH, entonces el CEDS no hubiera podido, a mi parecer, argüir desde el art. 11.1 CSE como lo ha hecho. Solo porque tal requisito es lesivo de la integridad, según ha establecido el TEDH, puede entenderse que el derecho a la protección de la salud también es vulnerado si se impone un radical tratamiento médico para ejercer el derecho a la identidad sexual, pues entonces el consentimiento a la intervención estaría viciado.

En definitiva, tanto el TEDH como el CEDS enjuician la misma situación: el requisito de un tratamiento médico de esterilización o que pueda implicarla. Cada órgano del Consejo de Europa funda, claro está, su respectiva apreciación en su propio canon de enjuiciamiento: el TEDH principalmente en el art. $8 \mathrm{CEDH}$, pero también en el art. 3, mientras que el CEDS aborda la cuestión desde el art. 11.1 CSE.

$\mathrm{Y}$ en esta tesitura resultaba claro que el CEDS tenía que incluir por primera vez la idea de consentimiento a los tratamientos médicos dentro del derecho reconocido en el art. 11.1 CSE, y lo pudo hacer con naturalidad, porque las intervenciones médicas siempre suponen una injerencia en la integridad física y eventualmente psicológica. Pero en relación con los transexuales, el CEDS necesitaba, en mi opinión, la decisión del TEDH interpretando que el requisito de esterilización era contrario al $\mathrm{CEDH}$. Solo después de este pronunciamiento del TEDH, el CEDS pudo considerar las obligaciones negativas y positivas de los Estados al respecto. Sobre las primeras, infiriendo que no pueden perturbar el ejercicio del derecho a acceder a esos tratamientos médicos que se ponen a su disposición (obligación positiva), pero no imponiéndolos, haciendo correr a los sujetos un 
riesgo para su salud. No puede reputarse legítimo que los poderes públicos interfieran en la decisión libre del individuo sobre si someterse o no a tales tratamientos, decisión que simultáneamente es ejercicio del derecho a la identidad y de su derecho a la salud, ni tampoco pueden estos imponerse porque el Estado faltaría entonces a su deber de abstenerse (obligación negativa) de toda interferencia.

En el centro de la decisión del CEDS está la noción de consentimiento, pues, en línea con el TEEDH, considera que todo tratamiento médico debe ser aceptado de manera libre e informada por el paciente. Aquí radica la novedad de esta decisión, porque tal cosa, por lo demás evidente, no había tenido ocasión de afirmarla el CEDS. Frente al razonamiento del Gobierno checo que defendía la adecuación de la legislación nacional con la que se regulaba el consentimiento, el CEDS afirma que no puede reputarse legítimo un sacrificio tan radical de la integridad, que viene forzada en la medida en la que el que desea el cambio en su identidad, para obtenerlo, debe someterse a los riesgos que tal tratamiento conlleva. Porque es obvio que muchos transgenéros aspiran a ser transexuales, es decir, que libremente optan por someterse a la reasignación quirúrgica de su sexo, pero también es cierto que otros transgéneros, por razones médicas o de otro tipo, no pueden o no quieren arrostrar los riesgos que supone, y tanto la decisión del TEDH como la del CEDS vienen a asegurar sus derechos a la identidad de género y a la salud.

\section{CONCLUSIÓN}

Como otros grupos sociales con peculiaridades, el grupo de transgéneros inició hace muchos años una batalla en el plano jurídico que ha ido ganando con resoluciones de instancias nacionales y también internacionales que hemos comentado. Se trataba no tanto de crear derechos específicos de los transexuales - que por ser específicos serían privilegios- como de concretar de qué forma los derechos reconocidos a todos pueden ejercerlos este tipo de personas. Todos podemos someternos a una intervención quirúrgica consintiéndola, pero cuando un transexual se somete a una reasignación de sexo o a otros tratamientos, además de ejercer su derecho a la integridad, está ejerciendo el de identidad sexual transformando radicalmente la suya. Dar una calificación jurídica a esta situación desde la óptica de los derechos fundamentales ha sido una tarea que en particular el TEDH ha venido realizando desde hace ya años y que con el caso 
A. P., Garçon y Nicot parece haber cerrado fijando un estándar que obligará sin duda a cambiar muchas legislaciones nacionales de Estados miembros del Consejo de Europa que han quedado fuera de él. En España, desde 2007, existe una legislación en la materia, en principio no divergente con esta doctrina, pero que es posible que pronto sea modificada.

A las decisiones del TEDH ha seguido, como también hemos visto, otra del CEDS reforzándola desde el derecho a la protección de la salud. Y en el ámbito interamericano la opinión consultiva de la Corte de San José sobre estas materias también forzará cambios legislativos internos en aquella zona del mundo. El conjunto ha acabado por alumbrar un entendimiento de los derechos de todos que no impida, sino que fomente, su ejercicio por parte de los transexuales. 